\title{
The cytoprotective effects of 7,8-dihydroxyflavone against oxidative stress are mediated by the upregulation of Nrf2-dependent HO-1 expression through the activation of the PI3K/Akt and ERK pathways in $\mathrm{C2C12}$ myoblasts
}

\author{
JI SOOK KANG ${ }^{1 *}$, IL-WHAN CHOI ${ }^{2 *}$, MIN HO HAN ${ }^{1,3}$, GI-YOUNG KIM ${ }^{4}$, SU HYUN HONG ${ }^{3}$, CHEOL PARK $^{5}$, \\ HYE JIN HWANG ${ }^{1,6}$, CHEOL MIN KIM ${ }^{7}$, BYUNG WOO KIM ${ }^{1,8}$ and YUNG HYUN CHOI ${ }^{1,3}$ \\ ${ }^{1}$ Blue-Bio Industry RIC and Anti-Aging Research Center, Dongeui University, Busan 614-714; ${ }^{2}$ Department of Microbiology, \\ College of Medicine, Inje University, Busan 608-756; ${ }^{3}$ Department of Biochemistry, Dongeui University College of \\ Korean Medicine, Busan 614-052; ${ }^{4}$ Laboratory of Immunobiology, Department of Marine Life Sciences, \\ Jeju National University, Jeju 690-756; Departments of ${ }^{5}$ Molecular Biology and ${ }^{6}$ Food and Nutrition, \\ College of Natural Sciences and Human Ecology, Dongeui University, Busan 614-714; ${ }^{7}$ Department of Biochemistry, \\ Busan National University College of Medicine, Yangsan, Gyeongsangnam-do 626-870; ${ }^{8}$ Department of Life Science and \\ Biotechnology, College of Natural Sciences and Human Ecology, Dongeui University, Busan 614-714, Republic of Korea
}

Received March 8, 2015; Accepted June 10, 2015

DOI: $10.3892 / \mathrm{ijmm} .2015 .2256$

\begin{abstract}
Recent studies have demonstrated that 7,8-dihydroxyflavone (7,8-DHF), a newly identified tyrosine kinase receptor B agonist, is a potent antioxidant agent. The present study was designed to confirm the cytoprotective effects of 7,8-DHF against oxidative stress-induced cellular damage and to further elucidate the underlying mechanisms in $\mathrm{C} 2 \mathrm{C} 12$ myoblasts. We found that 7,8-DHF attenuated hydrogen peroxide $\left(\mathrm{H}_{2} \mathrm{O}_{2}\right)$-induced growth inhibition and exhibited scavenging activity against intracellular reactive oxygen species (ROS) that were induced by $\mathrm{H}_{2} \mathrm{O}_{2}$. We also observed that 7,8-DHF significantly attenuated $\mathrm{H}_{2} \mathrm{O}_{2}$-induced comet tail formation, and decreased the phosphorylation levels of the histone, $\mathrm{H} 2 \mathrm{AX}$, as well as the number of Annexin V-positive cells, suggesting that 7,8-DHF prevents $\mathrm{H}_{2} \mathrm{O}_{2}$-induced DNA damage and cell apoptosis. Furthermore, 7,8-DHF increased the levels of heme oxygenase-1 (HO-1), which is a potent antioxidant enzyme associated with the induction and phosphorylation of
\end{abstract}

Correspondence to: Dr Yung Hyun Choi, Department of Biochemistry, Dongeui University College of Korean Medicine, San 45, Yangjung-dong, Busanjin-gu, Busan 614-052, Republic of Korea E-mail: choiyh@deu.ac.kr

*Contributed equally

Key words: 7,8-dihydroxyflavone, reactive oxygen species, nuclear factor-erythroid 2-related factor 2/heme oxygenase-1, phosphatidylinositol 3-kinase/Akt, extracellular signal-regulated kinase nuclear factor-erythroid 2-related factor 2 (Nrf2), as well as the translocation of Nrf2 from the cytosol to the nucleus. However, the protective effects of 7,8-DHF against $\mathrm{H}_{2} \mathrm{O}_{2}$-induced ROS generation and growth inhibition were significantly diminished by zinc protoporphyrin IX, an HO-1 competitive inhibitor. Moreover, the potential of 7,8-DHF to mediate HO-1 induction and protect the cells against $\mathrm{H}_{2} \mathrm{O}_{2}$-mediated growth inhibition was abrogated by transient transfection with Nrf2-specific small interfering RNA (siRNA). In addition, 7,8-DHF induced the activation of Akt, a downstream target of phosphatidylinositol 3-kinase (PI3K), and also that of extracellular signal-regulated kinase (ERK) and p38 mitogen-activated protein kinase (MAPK), while specific inhibitors of PI3K and ERK, but not a p38 MAPK inhibitor, abolished the 7,8-DHF induced HO-1 upregulation and Nrf2 induction and phosphorylation. Collectively, these results demonstrate that 7,8-DHF augments the cellular antioxidant defense capacity through activation of the Nrf2/HO-1 pathway, which also involves the activation of the PI3K/Akt and ERK pathways, thereby protecting $\mathrm{C} 2 \mathrm{C} 12$ myoblasts from $\mathrm{H}_{2} \mathrm{O}_{2}$-induced oxidative cytotoxicity.

\section{Introduction}

Oxidative stress, caused by the increased production of reactive oxygen species (ROS), is the pathological basis of a number of chronic diseases. Under physiological conditions, low levels of ROS are scavenged effectively by the cellular antioxidant defense system. However, the excessive production of ROS causes destructive and irreversible damage to cellular components, including nucleic acids, proteins, lipids and other macromolecules $(1,2)$. Therefore, the induction of antioxidant enzymes plays an important role in the cytoprotection against oxidative stress. 
Nuclear factor erythroid 2-related factor 2 (Nrf2) is a master cellular sensor for oxidative stress, and it represents the primary response to changes in the redox state of cells (3-5). Under basal conditions, Nrf2 is sequestered in the cytoplasm by the inhibitory partner known as the Kelch-like ECH-associated protein-1 (Keap1). Keap1 functions as an adaptor for the Cullin 3 (Cul3)-based E3 ligase and regulates the proteasomal degradation of $\mathrm{Nrf} 2(3,4)$. Upon stimulation, Nrf-2 dissociates from Keap1, and the unbound Nrf-2 translocates to the nucleus $(5,6)$, where it sequentially binds to the antioxidant-response element (ARE), resulting in a cytoprotective response which is characterized by an upregulation of antioxidant enzymes and decreased sensitivity to damage from oxidative stress $(3,7,8)$. The gene families regulated by the ARE include phase II metabolizing/detoxifying enzymes, such as heme oxygenase-1 (HO-1) and $\mathrm{NAD}(\mathrm{P}) \mathrm{H}$ :quinone oxidoreductase 1 (NQO1), as well as various antioxidants. Several natural and synthetic compounds are capable of exerting protective effects not only by free radical scavenging, but also by augmenting the expression of cytoprotective and/or antioxidant genes through the Nrf2-driven ARE signaling pathway $(7,9)$. Nrf2 is thus considered a key molecular target of antioxidant enzyme inducers, which convert ROS into less reactive and less damaging forms. This is the primary defense mechanism against ROS.

Flavonoids are natural polyphenolic compounds that are widely distributed in celery and parsley, as well as in a number of other vegetables and herbs (10). There is increasing evidence indicating that flavonoids have diverse biological functions, including antioxidant and anti-inflammatory activities (10), although the underlying mechanisms are not yet fully understood. The flavone derivative 7,8-dihydroxyflavone (7,8-DHF) has been identified as a selective agonist for tyrosine receptor kinase B (TrkB) and activates its downstream signaling cascade (11), thereby exerting potent neuroprotective and neurotrophic effects against Parkinson's disease and other neurological disorders (12). Previous studies have demonstrated that 7,8-DHF is a potent antioxidant and that it protects cells against oxidative stress-induced damage by reducing ROS production (13-16). In our previous studies, we demonstrated that due to its anti-inflammatory properties 7,8-DHF may be used in the treatment of inflammatory and neurodegenerative diseases $(17,18)$. Previous studies have also confirmed that the cytoprotective effects of 7,8-DHF against oxidative stress are associated with the Nrf2-mediated induction of HO-1 expression in lung fibroblasts and keratinocytes (19-21). However, to date, to the best of our knowledge, there is available no information on the beneficial effects of 7,8-DHF against oxidative stress in myoblasts. Therefore, in this study, we aimed to further elucidate the intracellular pathways and determine whether 7,8-DHF has the ability to activate Nrf2 and induce its downstream target genes in murine-derived $\mathrm{C} 2 \mathrm{C} 12$ myoblasts.

\section{Materials and methods}

Cell culture and 7,8-DHF treatment. C2C12 myoblasts obtained from the American Type Culture Collection (ATCC, Manassas, VA, USA) were grown in Dulbecco's modified Eagle's medium (DMEM) supplemented with $10 \%$ fetal bovine serum (FBS) and $100 \mu \mathrm{g} / \mathrm{ml}$ penicillin/streptomycin (both from WelGENE Inc., Daegu, Korea) in a humidi- fied $5 \% \mathrm{CO}_{2}$ atmosphere at $37^{\circ} \mathrm{C}$. 7,8-DHF (purity, $\geq 98 \%$; Sigma-Aldrich, St. Louis, MO, USA) was dissolved in dimethyl sulfoxide (DMSO; Sigma-Aldrich) and adjusted to final concentrations using complete DMEM prior to use. In order to investigate the effects of PI3K/Akt and MAPKs pathways on the induction of Nrf2, p-Nrf2 and HO-1 by 7,8-DHF, LY294002 (an inhibitor of Akt), PD98059 (an inhibitor of ERK), SB203580 (an inhibitor of p38) and SP600125 (an inhibitor of JNK) were obtained from Calbiochem (San Diego, CA, USA).

Cell viability assay. As a measure of the overall levels of cell viability, the $\mathrm{C} 2 \mathrm{C} 12$ myoblasts were assessed by 3-(4,5-dimethylthiazol-2-yl)-2,5-diphenyltetrazolium bromide (MTT; Sigma-Aldrich) assay. Briefly, the C2C12 myoblasts were seeded in 6 -well plates at a density of $1 \times 10^{5}$ cells/well. Following $24 \mathrm{~h}$ of incubation, the cells were treated with the indicated concentrations of 7,8-DHF $(2.5,5,10,15$ or $20 \mu \mathrm{M})$ in the absence or presence of hydrogen peroxide $\left(\mathrm{H}_{2} \mathrm{O}_{2}\right)$ and/or zinc protoporphyrin IX (ZnPP, a specific inhibitor of HO-1; Sigma-Aldrich) for the indicated periods of time (24 or $6 \mathrm{~h}$ ). MTT working solution was then added to the culture plates followed by incubation at $37^{\circ} \mathrm{C}$ for $3 \mathrm{~h}$. The culture supernatant was completely removed from the wells, and DMSO was added to dissolve the formazan crystals. The absorbance of each well was then measured at $540 \mathrm{~nm}$ using a microplate reader (Molecular Devices, Palo Alto, CA, USA). The protective effects of 7,8-DHF against growth inhibition were assessed as a percentage of cell viability, and the vehicle $(0.05 \mathrm{mM}$ DMSO)-treated cells were considered $100 \%$ viable.

Comet assay (single cell gel electrophoresis). The cell suspension was mixed with $0.5 \%$ low melting agarose (LMA) at $37^{\circ} \mathrm{C}$, and the mixture was spread on a fully frosted microscopic slide precoated with $1 \%$ normal melting agarose (NMA). After the solidification of the agarose, the slide was covered with $0.5 \%$ LMA and then immersed in a lysis solution $[2.5 \mathrm{M} \mathrm{NaCl}$, $100 \mathrm{mM}$ Na-ethylenediaminetetraacetic acid (EDTA), $10 \mathrm{mM}$ Tris, $1 \%$ Triton X-100 and 10\% DMSO, pH 10] for $1 \mathrm{~h}$ at $4^{\circ} \mathrm{C}$. The slides were then placed in a gel electrophoresis apparatus containing $300 \mathrm{mM} \mathrm{NaOH}$ and $10 \mathrm{mM}$ Na-EDTA (pH 13) for $40 \mathrm{~min}$ to allow for the unwinding of the DNA and the expression of alkali-labile damage. An electrical field was then used $(300 \mathrm{~mA}, 25 \mathrm{~V})$ for $20 \mathrm{~min}$ at $4^{\circ} \mathrm{C}$ to draw the negatively charged DNA toward the anode. Following electrophoresis, the slides were washed 3 times for $5 \mathrm{~min}$ at $4^{\circ} \mathrm{C}$ in neutralizing buffer $(0.4 \mathrm{M}$ Tris, $\mathrm{pH} 7.5)$, followed by staining with $20 \mu \mathrm{g} / \mathrm{ml}$ propidium iodide (PI; Sigma-Aldrich). The slides were examined under a fluorescence microscope (Carl Zeiss, Oberkochen, Germany).

Protein extraction, electrophoresis and western blot analysis. Whole-cell protein extracts from the $\mathrm{C} 2 \mathrm{C} 12$ myoblasts were prepared with cell lysis buffer $(20 \mathrm{mM}$ sucrose, $1 \mathrm{mM}$ EDTA, $20 \mu \mathrm{M}$ Tris- $\mathrm{HCl}$, pH 7.2, $1 \mathrm{mM}$ dithiothreitol, $10 \mathrm{mM}$ $\mathrm{KCl}, 1.5 \mathrm{mM} \mathrm{MgCl}$ and $5 \mu \mathrm{g} / \mathrm{ml}$ aprotinin) for $30 \mathrm{~min}$. In a parallel experiment, nuclear proteins were prepared using nuclear extraction reagents (Pierce Biotechnology, Rockford, IL, USA) according to the manufacturer's instructions. The protein extracts were quantified using the Bio-Rad kit (Pierce Biotechnology). For western blot analysis, equal amounts of 

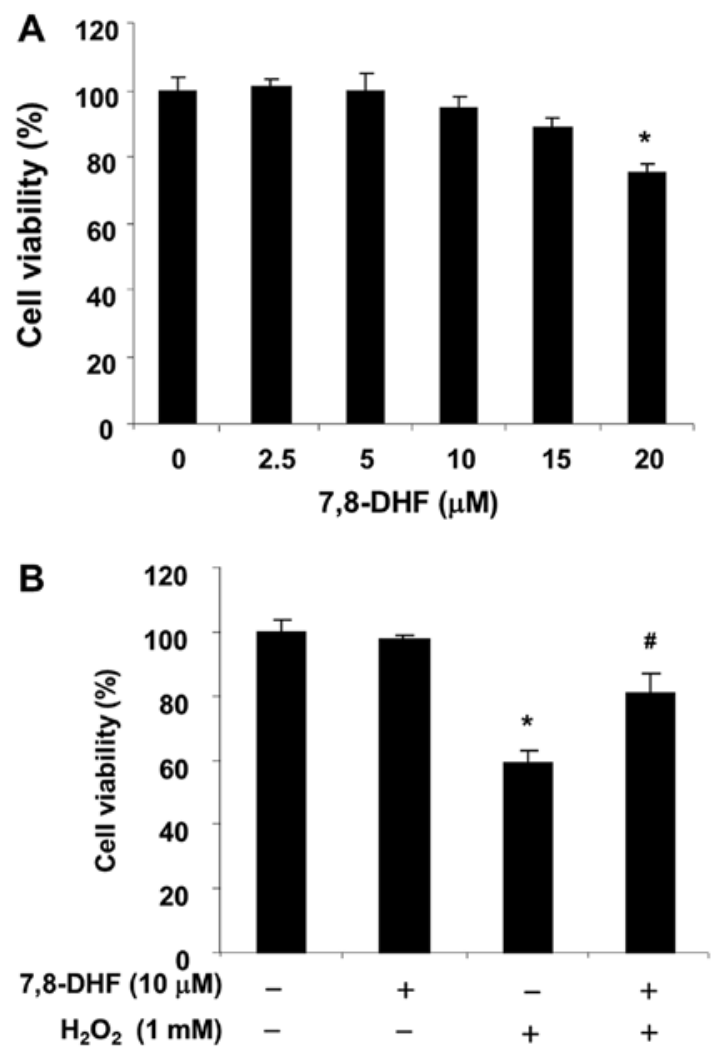

Figure 1. Effects of 7,8-dihydroxyflavone (7,8-DHF) on $\mathrm{H}_{2} \mathrm{O}_{2}$-induced growth inhibition of $\mathrm{C} 2 \mathrm{C} 12$ myoblasts. Cells were treated with various concentrations of 7,8-DHF for $24 \mathrm{~h}(\mathrm{~A})$ or pre-treated with $10 \mu \mathrm{M}$ 7,8-DHF for $1 \mathrm{~h}$ and then incubated with or without $1 \mathrm{mM} \mathrm{H}_{2} \mathrm{O}_{2}$ for $6 \mathrm{~h}$ (B). Cell viability was assessed by MTT reduction assay. The results are the means \pm SD obtained from 3 independent experiments. ${ }^{*} \mathrm{P}<0.05$ compared with the control group; ${ }^{~} \mathrm{P}<0.05$ compared with the $\mathrm{H}_{2} \mathrm{O}_{2}$-treated group.

protein extracts were separated by denaturing sodium dodecyl sulfate (SDS)-polyacrylamide gels and transferred electrophoretically onto nitrocellulose membranes (Schleicher \& Schuell, Keene, NH, USA). The membranes were then incubated overnight at $4^{\circ} \mathrm{C}$ with primary antibodies, probed with enzyme-linked secondary antibodies [mouse IgG, HRP-linked whole antibody (NA931) and rabbit IgG, HRP-linked whole antibody (NA934), Amersham Corp., Arlington Heights, IL, USA)] for $1 \mathrm{~h}$ at room temperature, and detected using an enhanced chemiluminescence (ECL) detection system (all from Amersham Co.). The antibodies used were as follows: iNOS (1:500; SC-7271, mouse monoclonal; Santa Cruz Biotechnology, Inc., Santa Cruz, CA, USA), TNF- $\alpha$ (1:500; \#3707S, rabbit polyclonal; Cell Signaling Technology, Inc., Danvers, MA, USA), IL-1 $\beta$ (1:500; SC-7884, rabbit polyclonal), NF- $\mathrm{B}$ p65 (1:500; SC-109, rabbit polyclonal), I $\mathrm{B} \alpha$ (1:500; SC-371, rabbit polyclonal), Akt (1:500; SC-8312, rabbit polyclonal), p-Akt (1:500; SC-101629, rabbit polyclonal), ERK (1:1,000; SC-154, rabbit polyclonal; all from Santa Cruz Biotechnology, Inc.), p-ERK (1:500; \#9106S, mouse monoclonal; Cell Signaling Technology, Inc.), p38 (1:1,000; SC-535, rabbit polyclonal; Santa Cruz Biotechnology, Inc.), p-p38 (1:500; \#9211S, rabbit polyclonal), JNK (1:1,000; \#9252S, rabbit polyclonal), p-JNK (1:500; \#9255S, mouse monoclonal; all from Cell Signaling Technology, Inc.), Nrf2 (1:500; SC-13032, rabbit polyclonal; Santa Cruz Biotechnology, Inc.), p-Nrf2 (1:500; ab76026, rabbit monoclonal; Abcam, Inc., Cambridge, UK),
HO-1 (1:500; SC-136960, mouse monoclonal), Lamin B (1:500; SC-6216, goat polyclonal) and $\beta$-actin $(1: 1,000$; sc-1616, goat polyclonal; all from Santa Cruz Biotechnology, Inc.). Actin and poly(ADP ibose) polymerase (PARP) were used as the internal controls of the total cellular and nuclear proteins, respectively.

Assessment of apoptosis by flow cytometry. To quantitatively assess the cell apoptotic rate, a fluorescein-conjugated Annexin V (Annexin V-FITC) staining assay was performed according to the manufacturer's instructions (BD Biosciences, San Jose, CA, USA). Briefly, the cells were stained with $5 \mu 1$ Annexin V-FITC and $5 \mu \mathrm{l}$ PI. Following incubation for $15 \mathrm{~min}$ at room temperature in the dark, the degree of apoptosis was quantified as a percentage of the Annexin V-positive and PI-negative cells by flow cytometry, as previously described (22).

Measurement of ROS production. The intracellular accumulation of ROS was determined using the fluorescent probe, 2',7'-dichlorodihydrofluorescein diacetate (H2DCFDA; obtained from Molecular Probes, Eugene, OR, USA). In order to monitor the generation of ROS, the cells were treated with $5 \mathrm{mM}$ N-acetyl-L-cysteine (NAC; Sigma-Aldrich) for $30 \mathrm{~min}$ and then treated with 7,8-DHF for $6 \mathrm{~h}$. After the addition of $10 \mu \mathrm{M} \mathrm{H} 2 \mathrm{DCFDA}$ for $20 \mathrm{~min}$ at room temperature in the dark, ROS production in the cells was monitored using a flow cytometer (BD Biosciences) with CellQuest Pro software, as previously described (23).

Transfection with small interfering RNA (siRNA). Nrf2 siRNA and control siRNA were purchased from Santa Cruz Biotechnology, Inc. The cells were transfected with the siRNAs according to the manufacturer's instructions using Lipofectamine 2000 Transfection Reagent (Life Technologies, Carlsbad, CA, USA). For transfection, the cells were seeded in 6-well culture plates and incubated with the control siRNA or Nrf2 siRNA at $50 \mathrm{nM}$ for $6 \mathrm{~h}$ in serum-free OPTI-MEM medium. Following incubation, the transfected cells were subjected to treatment as described in the figure legends and as previously described (24).

Statistical analysis. Data are expressed as the means \pm standard deviation (SD). One-way analysis of variance (ANOVA) was used for comparisons in the experiments with multiple time points and concentrations. When ANOVA indicated statistical significance, Duncan's multiple range test was used to determine which means were significantly different. A probability value of $\mathrm{P}<0.05$ was used as the criterion for statistical significance.

\section{Results}

Protective effects of 7,8-DHF against $\mathrm{H}_{2} \mathrm{O}_{2}$-induced cytotoxicity to $C 2 C 12$ myoblasts. We first determined the effects of 7,8-DHF on the viability of $\mathrm{C} 2 \mathrm{C} 12$ myoblasts by MTT assay. The cells were treated with a range of 7,8-DHF concentrations, from 2.5 to $20 \mu \mathrm{M}$ for $24 \mathrm{~h}$ (Fig. 1A). Treatment of the $\mathrm{C} 2 \mathrm{C} 12$ myoblasts with up to $10 \mu \mathrm{M} 7,8-\mathrm{DHF}$ did not result in any cytotoxic effects, whereas cell viability decreased in a dose-dependant manner following treatment with 7,8-DHF at concentrations $>10 \mu \mathrm{M}$ (Fig. 1A). Therefore, the dose of $10 \mu \mathrm{M}$ 7,8-DHF was selected as the optimal dose for examining the 
A

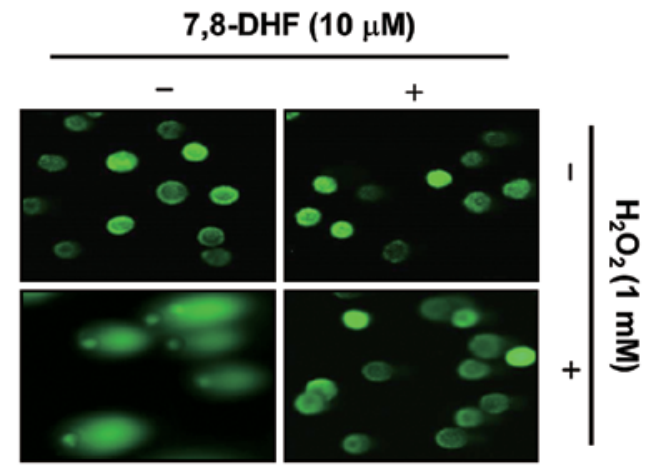

B

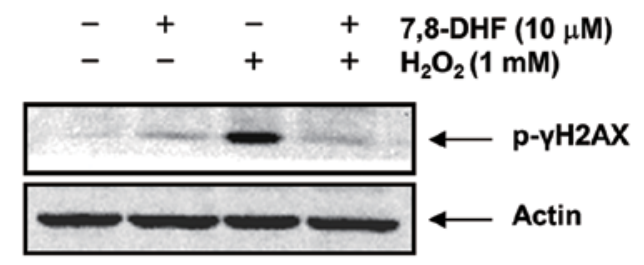

C

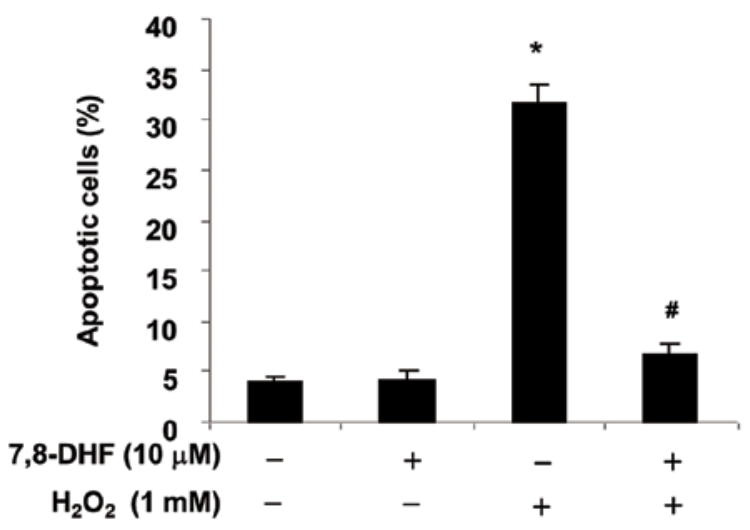

Figure 2. 7,8-Dihydroxyflavone (7,8-DHF) protects against $\mathrm{H}_{2} \mathrm{O}_{2}$-induced DNA damage and apoptosis in $\mathrm{C} 2 \mathrm{C} 12$ myoblasts. $\mathrm{C} 2 \mathrm{C} 12$ myoblasts were pretreated with $10 \mu \mathrm{M}$ 7,8-DHF for $1 \mathrm{~h}$ and then incubated with or without $1 \mathrm{mM}$ $\mathrm{H}_{2} \mathrm{O}_{2}$ for $6 \mathrm{~h}$. (A) To detect cellular DNA damage, a comet assay was performed and representative images of the comets were acquired using a fluorescence microscope (original magnification, x200). (B) The cells were lysed, and then equal amounts of cell lysates were separated on SDS-polyacrylamide gels and transferred onto nitrocellulose membranes. The membranes were probed with specific antibodies against phosphorylated-histone $\mathrm{H} 2 \mathrm{AX}(\gamma \mathrm{H} 2 \mathrm{AX})$ and actin, as an internal control, and the proteins were visualized using an enhanced chemiluminescence (ECL) detection system. A representative blot from 3 independent experiments is shown. (C) The cells were also stained with Annexin V-FITC and propidium iodide (PI), and the percentages of apoptotic cells (Annexin $\mathrm{V}^{+}$cells) were then analyzed by flow cytometry. The results are the means \pm SD obtained from 3 independent experiments. ${ }^{*} \mathrm{P}<0.05$ compared with the control group; ${ }^{~} \mathrm{P}<0.05$ compared with the $\mathrm{H}_{2} \mathrm{O}_{2}$-treated group.

cytoprotective effects of 7,8-DHF against $\mathrm{H}_{2} \mathrm{O}_{2}$-induced cell damage. To examine the protective effects of 7,8-DHF against $\mathrm{H}_{2} \mathrm{O}_{2}$-induced cytotoxicity, we treated the $\mathrm{C} 2 \mathrm{C} 12$ myoblasts with $10 \mu \mathrm{M} 7,8$-DHF $1 \mathrm{~h}$ prior to exposure to $\mathrm{H}_{2} \mathrm{O}_{2}$, and cell viability was then measured by MTT assay. Following exposure to $1 \mathrm{mM} \mathrm{H}_{2} \mathrm{O}_{2}$ alone, cell viability was reduced to approximately $60 \%$ at $6 \mathrm{~h}$, whereas the $\mathrm{H}_{2} \mathrm{O}_{2}$-induced decrease in of cell viability was significantly attenuated by pre-treatment with 7,8-DHF (Fig. 1B). These results clearly indicate that the exposure of $\mathrm{C} 2 \mathrm{C} 12$ myoblasts to 7,8-DHF confers a significant protective effect against oxidative stress.
7,8-DHF prevents $\mathrm{H}_{2} \mathrm{O}_{2}$-induced DNA damage and apoptosis in $\mathrm{C} 2 \mathrm{C} 12$ cells. As DNA strand breakage is considered one of the most frequent types of damage that can be induced by oxidative stress (25), we examined the effects of 7,8-DHF on $\mathrm{H}_{2} \mathrm{O}_{2}$-mediated damage to $\mathrm{C} 2 \mathrm{C} 12$ cell DNA using single-cell gel electrophoresis (comet assay) and western blot analysis. Treatment with $\mathrm{H}_{2} \mathrm{O}_{2}$ alone induced significant DNA damage in the $\mathrm{C} 2 \mathrm{C} 12$ myoblasts; however, this adverse effect was markedly reduced by pre-treatment with 7,8-DHF (Fig. 2A). In addition, our results revealed that the exposure of $\mathrm{C} 2 \mathrm{C} 12$ myoblasts to $\mathrm{H}_{2} \mathrm{O}_{2}$ resulted in an upregulation in the levels of the phosphorylated histone variant $\mathrm{H} 2 \mathrm{~A} . \mathrm{X}(\mathrm{p}-\gamma \mathrm{H} 2 \mathrm{AX})$ at serine 139 , a sensitive marker of DNA double-strand breaks (25); however, pre-treatment with 7,8-DHF resulted in a significant decrease in $\mathrm{p}-\gamma \mathrm{H} 2 \mathrm{AX}$ expression (Fig. 2B). In order to investigate the protective effects of 7,8-DHF against $\mathrm{H}_{2} \mathrm{O}_{2}$-induced apoptosis, the frequency of apoptotic cells was detected by flow cytometry, and the results revealed that the treatment of the cells with 7,8-DHF prior to exposure to $\mathrm{H}_{2} \mathrm{O}_{2}$ protected the $\mathrm{C} 2 \mathrm{C} 12$ myoblasts against apoptosis.

7,8-DHF modulates the $\mathrm{H}_{2} \mathrm{O}_{2}$-induced $\mathrm{ROS}$ generation in C2C12 cells. Using H2DCFDA assay, we then investigated whether 7,8-DHF affects intracellular ROS generation induced by exposure of the cells to $\mathrm{H}_{2} \mathrm{O}_{2}$. As expected, significantly increased levels of ROS were detected following the epxosure of the cells to $\mathrm{H}_{2} \mathrm{O}_{2}$ compared with the levels observed in the untreated cells; however, this increase in ROS levels was significantly inhibited by treatment with 7,8-DHF (Fig. 3A). Moreover, no fluorescence was detected in the cells treated with 7,8-DHF alone (data not shown), indicating that 7,8-DHF itself does not contribute to ROS generation. As a positive control, the ROS scavenger, NAC, was also used. Treatment with NAC attenuated the $\mathrm{H}_{2} \mathrm{O}_{2}$-induced ROS generation and decreased the apoptotic rate; it also reversed the decrease in cell viability induced by exposure to $\mathrm{H}_{2} \mathrm{O}_{2}$; these effects were similar to those of 7,8-DHF (Fig. 3B and C). The results indicate that the $\mathrm{H}_{2} \mathrm{O}_{2}$-induced induction of apoptosis and the reduction in cell viability are mediated by the generation of ROS, and that 7,8-DHF exerts a potent ROS-scavenging effect, protecting the $\mathrm{C} 2 \mathrm{C} 12$ myoblasts against $\mathrm{H}_{2} \mathrm{O}_{2}$-damage.

7,8-DHF enhances the expression of $\mathrm{HO}-1$, as well as $\mathrm{Nrf} 2$ phosphorylation and nuclear accumulation in C2C12 cells. It has been well documented that antioxidant enzymes play an important role against oxidative stress $(1,2)$; thus, we hypothesized that the effects of 7,8-DHF may be mediated by the induction of antioxidant enzymes. Treatment of the $\mathrm{C} 2 \mathrm{C} 12$ myoblasts with 7,8-DHF induced the protein expression of HO-1 in a time-dependent manner; however, the levels of the other antioxidant enzymes, NQO-1 and thioredoxin reductase 1 (TrxR1), were unaffected (Fig. 4A). Previous studies have demonstrated that, under normal conditions, Nrf-2 is inactive and bound in the cytosol by Keapl, and that the translocation of Nrf2 into the nucleus is essential for the transactivation of various target genes, such as HO-1. Moreover, the phosphorylation of Nrf2 at Ser40 by several kinases is also a critical process in its stabilization and nuclear translocation $(6,7)$. Therefore, in this study, we examined the phosphorylation and subcellular localization of Nrf2 following treatment with 

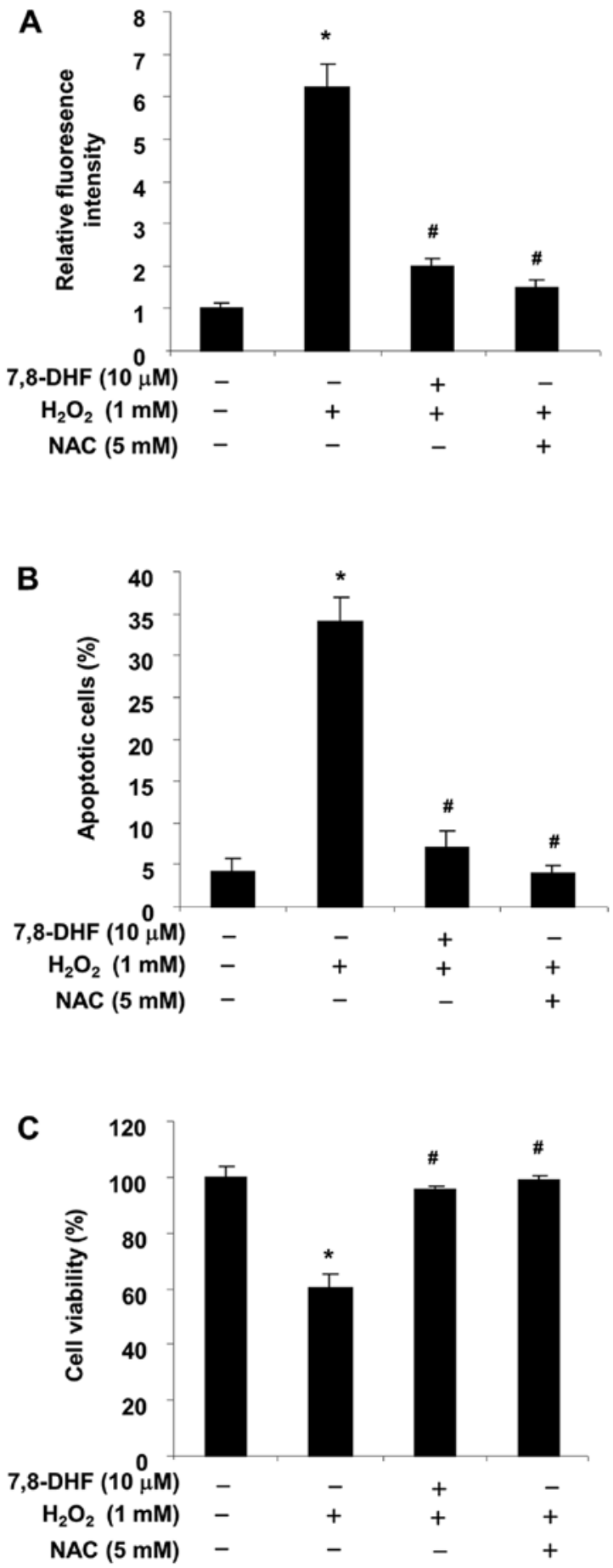

Figure 3. 7,8-Dihydroxyflavone (7,8-DHF) attenuates $\mathrm{H}_{2} \mathrm{O}_{2}$-induced reactive oxygen species (ROS) generation in $\mathrm{C} 2 \mathrm{C} 12$ myoblasts. $\mathrm{C} 2 \mathrm{C} 12$ myoblasts were pre-treated with $10 \mu \mathrm{M}$ 7,8-DHF or $5 \mathrm{mM} \mathrm{N}$-acetyl-L-cysteine (NAC) for $1 \mathrm{~h}$ and then stimulated with or without $1 \mathrm{mM} \mathrm{H}_{2} \mathrm{O}_{2}$ for $6 \mathrm{~h}$. (A) In order to monitor ROS production, the cells were incubated at $37^{\circ} \mathrm{C}$ in the dark for 20 min with new culture medium containing $10 \mu \mathrm{M}$ H2DCFDA. ROS generation was measured using a flow cytometer. The degree of (B) apoptosis and (C) cell viability were also assessed using a flow cytometer and MTT reduction assay, respectively. The results are the means \pm SD values obtained from 3 independent experiments. " $\mathrm{P}<0.05$ compared with the control group; ${ }^{\#} \mathrm{P}<0.05$ compared with the $\mathrm{H}_{2} \mathrm{O}_{2}$-treated group.

7,8-DHF in order to confirm the Nrf2-activating properties of 7,8-DHF. We observed that 7,8-DHF increased the expression levels of total and phosphorylated Nrf2 in a time-dependent
A 7,8-DHF $(10 \mu \mathrm{M})$

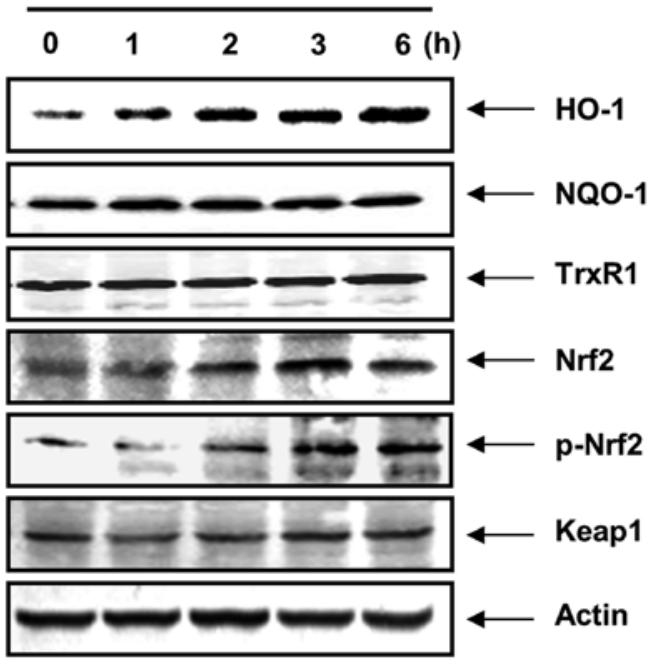

B 7,8-DHF (10 $\mu \mathrm{M})$

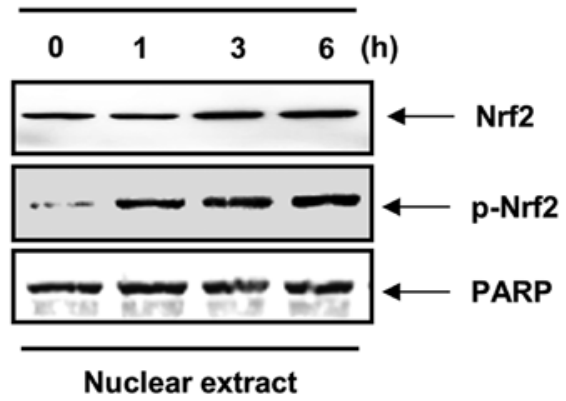

Figure 4. Induction of nuclear factor-erythroid 2-related factor 2 (Nrf2) and heme oxygenase-1 (HO-1) expression by 7,8-DHF in $\mathrm{C} 2 \mathrm{C} 12$ myoblasts. Cells were incubated with $10 \mu \mathrm{M} 7,8-\mathrm{DHF}$ for the indicated periods of time. (A) Total cellular or (B) nuclear proteins were separated on SDS-polyacrylamide gels and then transferred onto nitrocellulose membranes. The membranes were probed with the specific antibodies against HO-1, NQO-1, thioredoxin reductase 1 (TrxR1), Nrf2, p-Nrf2 and Kelch-like ECH-associated protein-1 (Keap1). Proteins were visualized using an enhanced chemiluminescence (ECL) detection system. Actin and poly(ADP-ribose) polymerase (PARP) were used as the internal controls of the total cellular and nuclear proteins, respectively.

manner (Fig. 4A). Furthermore, western blot analysis of the nuclear fraction revealed a significant augmentation of Nrf2 phosphorylation and nuclear accumulation following treatment with 7,8-DHF, in a time-dependent manner (Fig. 4B).

7,8-DHF upregulates HO-1 expression through the activation of Nrf2 in C2C12 cells. We developed a Nrf2 gene knockout model using siRNA transfection in order to demonstrate the importance of Nrf2 upregulation. The results of western blot analysis revealed that the silencing of Nrf2 using specific siRNA abolished the 7,8-DHF-induced increase in Nrf2 expression and HO-1 upregulation (Fig. 5A), which is evidence that the augmentation of HO-1 is mediated by Nrf2. To further confirm the involvement of $\mathrm{Nrf} 2$, the protective effects of 7,8-DHF against the $\mathrm{H}_{2} \mathrm{O}_{2}$-induced decrease in cell viability were determined in cells in which $\mathrm{Nrf} 2$ had been knocked down. As shown in Fig. 5B, siNrf2 transfection abrogated the cytoprotective effects of 7,8-DHF compared to the control siRNA-transfected cells, thus proving that 7,8-DHF diminishes 

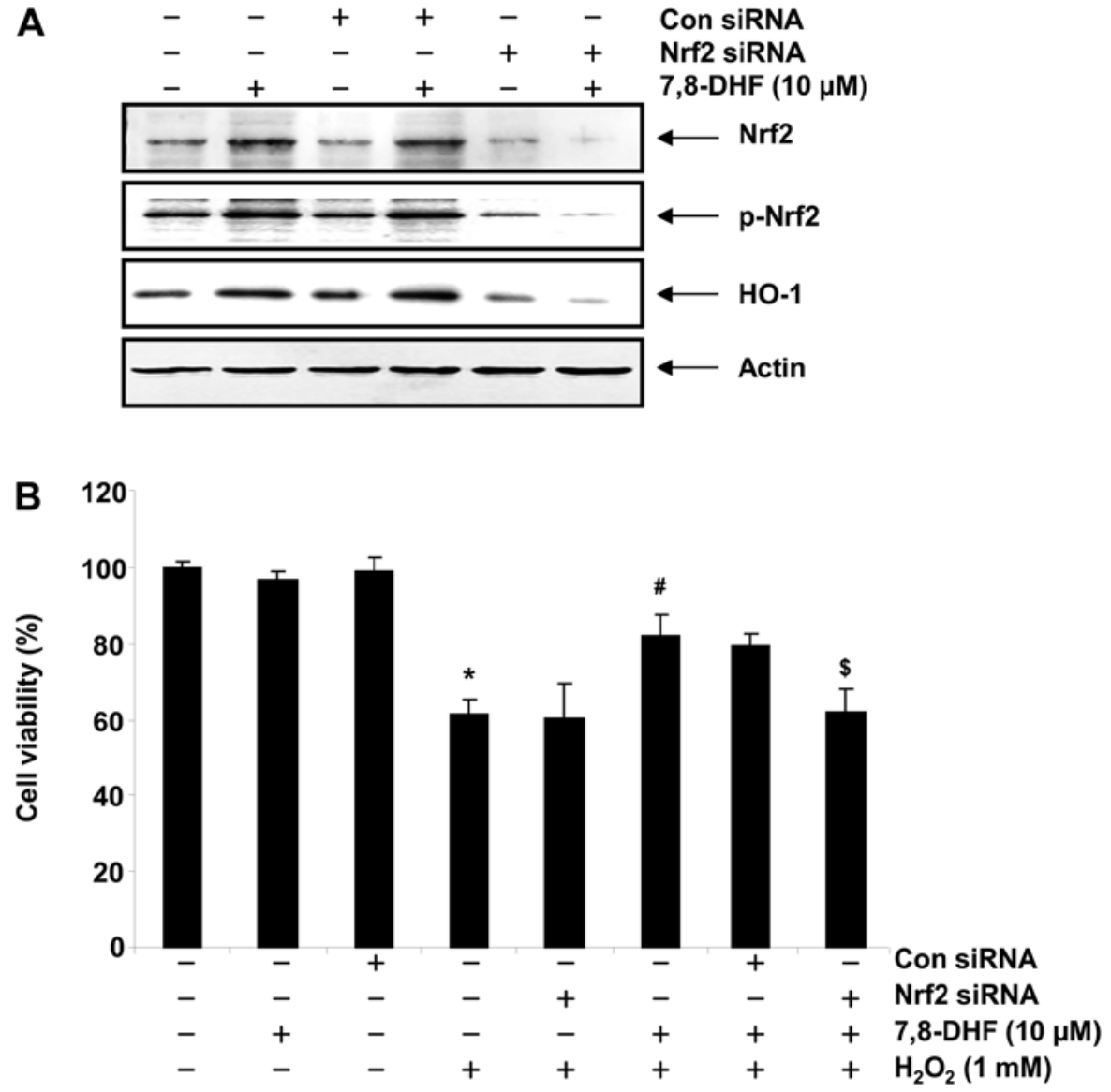

Figure 5. Nuclear factor-erythroid 2-related factor 2 (Nrf2)-mediated induction of heme oxygenase-1 (HO-1) expression by 7,8-dihydroxyflavone (7,8-DHF) in $\mathrm{C} 2 \mathrm{C} 12$ myoblasts. Cells were transfected with control (Con siRNA, as a negative control for RNA interference) and Nrf2 siRNA. After $24 \mathrm{~h}$, the cells were treated with $10 \mu \mathrm{M}$ 7,8-DHF for $6 \mathrm{~h}$ (A) or pre-treated with $10 \mu \mathrm{M}$ 7,8-DHF for $1 \mathrm{~h}$ and then stimulated with or without $1 \mathrm{mM} \mathrm{H}_{2} \mathrm{O}_{2}$ for $6 \mathrm{~h}$ (B). Cellular proteins were separated on SDS-polyacrylamide gels and then transferred onto nitrocellulose membranes (A). The membranes were probed with the specific antibodies against Nrf2, p-Nrf2 and HO-1. Proteins were visualized using an enhanced chemiluminescence (ECL) detection system. Actin was used as a loading control. (B) Cell viability was estimated by MTT assay. The results are the means \pm SD values obtained from 3 independent experiments " $\mathrm{P}<0.05$ compared with the control group; ${ }^{\#} \mathrm{P}<0.05$ compared with the $\mathrm{H}_{2} \mathrm{O}_{2}$-treated group; ${ }^{\mathrm{S}} \mathrm{P}<0.05$ compared with the $\mathrm{H}_{2} \mathrm{O}_{2}$ and 7,8 -DHF-treated group.

the $\mathrm{H}_{2} \mathrm{O}_{2}$-induced decrease in cell viability through the activation of the Nrf2/HO-1 signaling pathway.

7,8-DHF exerts protective effects against $\mathrm{H}_{2} \mathrm{O}_{2}$-induced damage in $\mathrm{C} 2 \mathrm{C} 12$ cells through the Nrf2/HO-1 pathway. To further determine whether the 7,8-DHF-induced antioxidant and cytoprotective activities against oxidative stress in $\mathrm{C} 2 \mathrm{C} 12$ cellsmyoblasts are mediated through the activation of the Nrf2/HO-1 pathway, the $\mathrm{C} 2 \mathrm{C} 12$ myoblasts were pre-incubated with or without a specific inhibitor of $\mathrm{HO}-1, \mathrm{ZnPP}$, and the levels of ROS and cell viability were then assessed. ZnPP abrogated the protective effects of 7,8-DHF against the $\mathrm{H}_{2} \mathrm{O}_{2}$-induced production of ROS and the decrease in cell viability (Fig. 6). These results indicate that 7,8-DHF exerts its protective effects by inducing the cellular defense mechanism against oxidative stress through the Nrf2-related cytoprotective pathway, and that HO-1 plays a crucial role in this protection of $\mathrm{C} 2 \mathrm{C} 12$ myoblasts.

The phosphatidylinositol 3-kinase (PI3K)/Akt and extracellular signal-regulated kinase (ERK) signaling pathways are associated with the Nrf2-mediated induction of HO-1 by 7,8-DHF in $\mathrm{C} 2 \mathrm{C} 12$ cells. A number of studies have noted that multiple phosphorylation cascades participate in the regulation of the translocation of Nrf2 and Nrf2-mediated HO-1 gene expression (26-28). Thus, to identify the upstream signaling events involved in the 7,8-DHF-mediated activation of Nrf2 and the induction of HO-1, the potential involvement of PI3K/Akt and mitogen-activated protein kinases (MAPKs) were explored. Although the total levels of Akt, a downstream target of PI3K, did not show a notable change, the Akt phosphorylation levels markedly increased following treatment with 7,8-DHF within 30 min (Fig. 7A). However, treatment with LY294002, a pharmacological inhibitor of PI3K, prevented the increase in the phosphorylation levels of $\mathrm{Nrf} 2$ and resulted in a blockade of $\mathrm{Nrf} 2$ and HO-1 induction which was by 7,8-DHF (Fig. 7B), suggesting that the 7,8-DHF-induced activation of the Nrf2/HO-1 pathway may be a process necessary to the PI3K cascade.

Subsequently, we investigated the effects of 7,8-DHF on the activation of MAPKs in C2C12 myoblasts. The increase in the phosphorylation levels of ERK and p38 MAPK were observed 30 min following treatment with 7,8-DHF and this increase was sustained for up to $2 \mathrm{~h}$ following treatment with 7,8-DHF. However, there were no notable changes observed in the phosphorylation levels of c-Jun N-terminal kinase (JNK) (Fig. 8A). When a selec- 


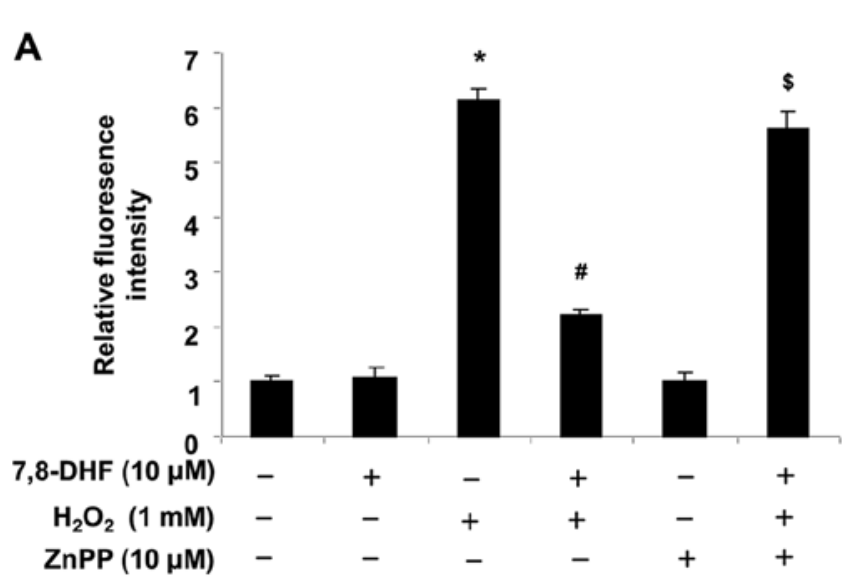

B

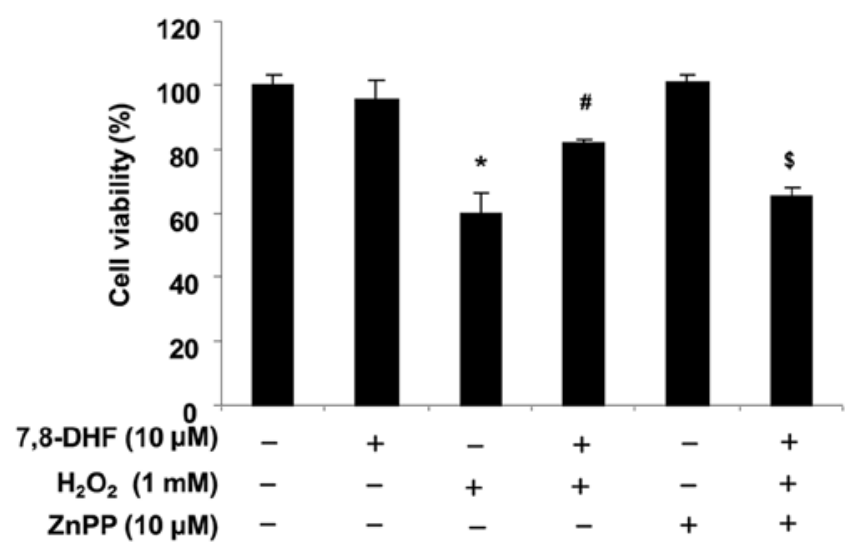

Figure 6. Effects of the inhibitor of heme oxygenase-1 (HO-1), zinc protoporphyrin IX ( $\mathrm{ZnPP})$, on the 7,8-dihydroxyflavone (7,8-DHF)-mediated attenuation of reactive oxygen species (ROS) formation and growth inhibition by $\mathrm{H}_{2} \mathrm{O}_{2}$ in $\mathrm{C} 2 \mathrm{C} 12$ myoblasts. Cells were pre-treated for $1 \mathrm{~h}$ with $10 \mu \mathrm{M} 7,8-\mathrm{DHF}$ and then treated for $6 \mathrm{~h}$ with or without $1 \mathrm{mM} \mathrm{H}_{2} \mathrm{O}_{2}$ in the absence or presence of $10 \mu \mathrm{M}$ $\mathrm{ZnPP}$. (A) ROS generation and (B) cell viabilit were then estimated. The results are the means \pm SD values obtained from 3 independent experiments. ${ }^{*} \mathrm{P}<0.05$ compared with the control group; ${ }^{\#} \mathrm{P}<0.05$ compared with the $\mathrm{H}_{2} \mathrm{O}_{2}$-treated group; ${ }^{\$} \mathrm{P}<0.05$ compared with the $\mathrm{H}_{2} \mathrm{O}_{2}$ and 7,8-DHF-treated group.

tive inhibitor of ERK (PD98059) was utilized, the induction and phosphorylation of Nrf2 were blocked and, accordingly, HO-1 induction was diminished (Fig. 8B). By contrast, inhibitors of p38 MAPK (SB203580) and JNK (SP600125) did not reduce the 7,8-DHF-induced HO-1 and Nrf2 expression or Nrf2 phosphorylation. These data indicate that the 7,8-DHF-mediated activation of the Nrf2/HO-1 pathway involves the ERK pathway, but not the p38 MAPK and JNK pathways. Taken together, these observations support the hypothesis that 7,8-DHF activates the PI3K/Akt and ERK pathways, which subsequently induces $\mathrm{Nrf} 2 / \mathrm{HO}-1$ activation in $\mathrm{C} 2 \mathrm{C} 12$ myoblasts.

\section{Discussion}

Previous studies have demonstrated that 7,8-DHF, a small-molecule TrkB agonist, has potent antioxidant potential $(4,13,14)$ as a direct free radical scavenger due to two adjacent hydroxyl groups which act as electron donors $(29,30)$. For example, it has been reported that this compound provides neuroprotection against glutamate-induced toxicity by increasing the cellular
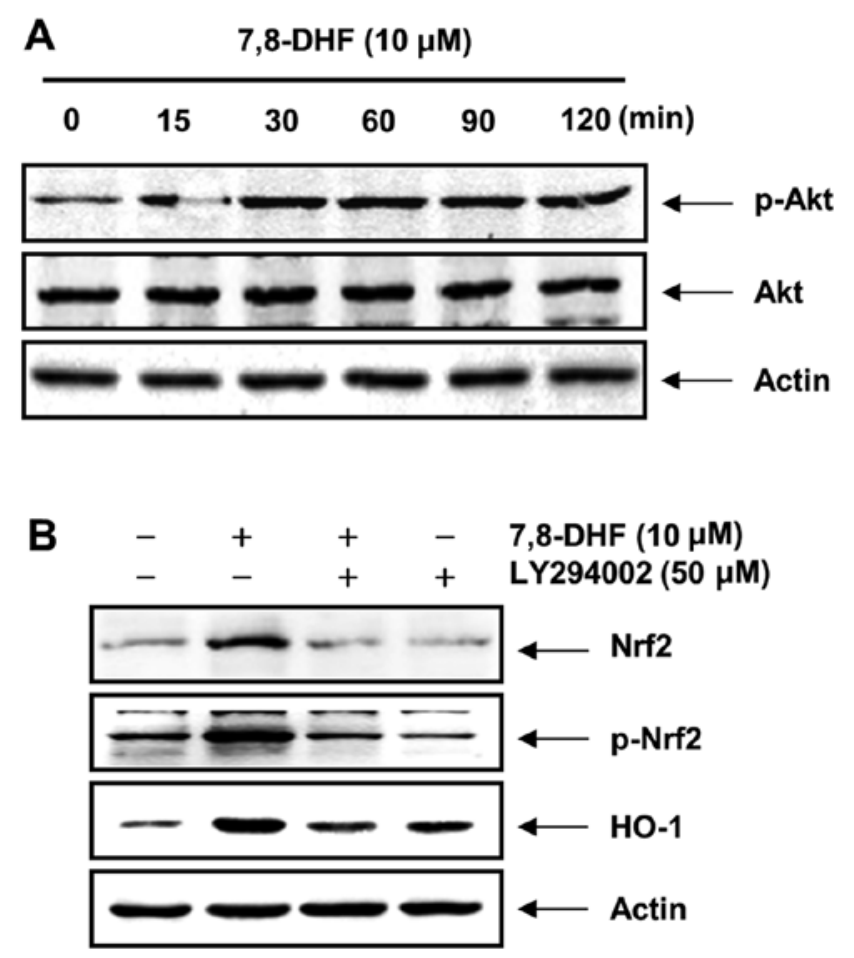

Figure 7.Involvement of the phosphatidylinositol3-kinase(PI3K)/Akt signaling pathway in the nuclear factor-erythroid 2-related factor 2 (Nrf2)-mediated induction of heme oxygenase-1 (HO-1) by 7,8-dihydroxyflavone (7,8-DHF) in $\mathrm{C} 2 \mathrm{C} 12$ myoblasts. Cells were treated with $10 \mu \mathrm{M} 7,8-\mathrm{DHF}$ for the indicated periods of time (A) or pre-treated for $1 \mathrm{~h}$ with or without LY294002, an inhibitor of PI3K, and then treated with $10 \mu \mathrm{M}$ 7,8-DHF for an additional $6 \mathrm{~h}$ (B). The cells were lysed and then equal amounts of cell lysates were separated on SDS-polyacrylamide gels and transferred onto nitrocellulose membranes. The membranes were probed with the indicated antibodies and the proteins were visualized using an enhanced chemiluminescence (ECL) detection system. Actin was used as an internal control.

glutathione levels and reducing ROS production caused by glutamate in hippocampal HT-22 cells (14). Zhang et al (15) demonstrated that 7,8-DHF exerts cytoprotective effects against oxidative stress by scavenging intracellular ROS and enhancing PI3K/Akt signaling in lung fibroblasts. Han et al (16) also indicated that 7,8-DHF prevents hydroxydopamine-induced DNA damage and apoptosis by directly scavenging intracellular ROS in PC12 pheochromocytoma cells. Recently, 7,8-DHF has been shown to activate the ERK- and Akt-Nrf2 signaling cascades in cultured human HaCaT keratinocytes, leading to the upregulation of HO-1 and cytoprotection against oxidative stress (19). 7,8-DHF has also been shown to protect cells from oxidative stress through the activation of the ERK/Nrf2/HO-1 signaling pathway in lung fibroblasts (20).

Oxidative stress which results from the overproduction of ROS and/or impaired antioxidan defense is a major cause of cell death in a number of pathological conditions $(1,2) \cdot \mathrm{H}_{2} \mathrm{O}_{2}$, one of the main ROS, may be involved in the formation of hydroxyl radicals, which are highly reactive and destructive substances that cause DNA damage in cells, and this in turn results in cell death $(31,32)$. In the present study, C2C12 myoblasts exposed to $\mathrm{H}_{2} \mathrm{O}_{2}$ exhibited a significant decrease in cell viability and an increased apoptosis; however, treatment with 7,8-DHF increased cell viability by inhibiting $\mathrm{H}_{2} \mathrm{O}_{2}$-induced apop- 


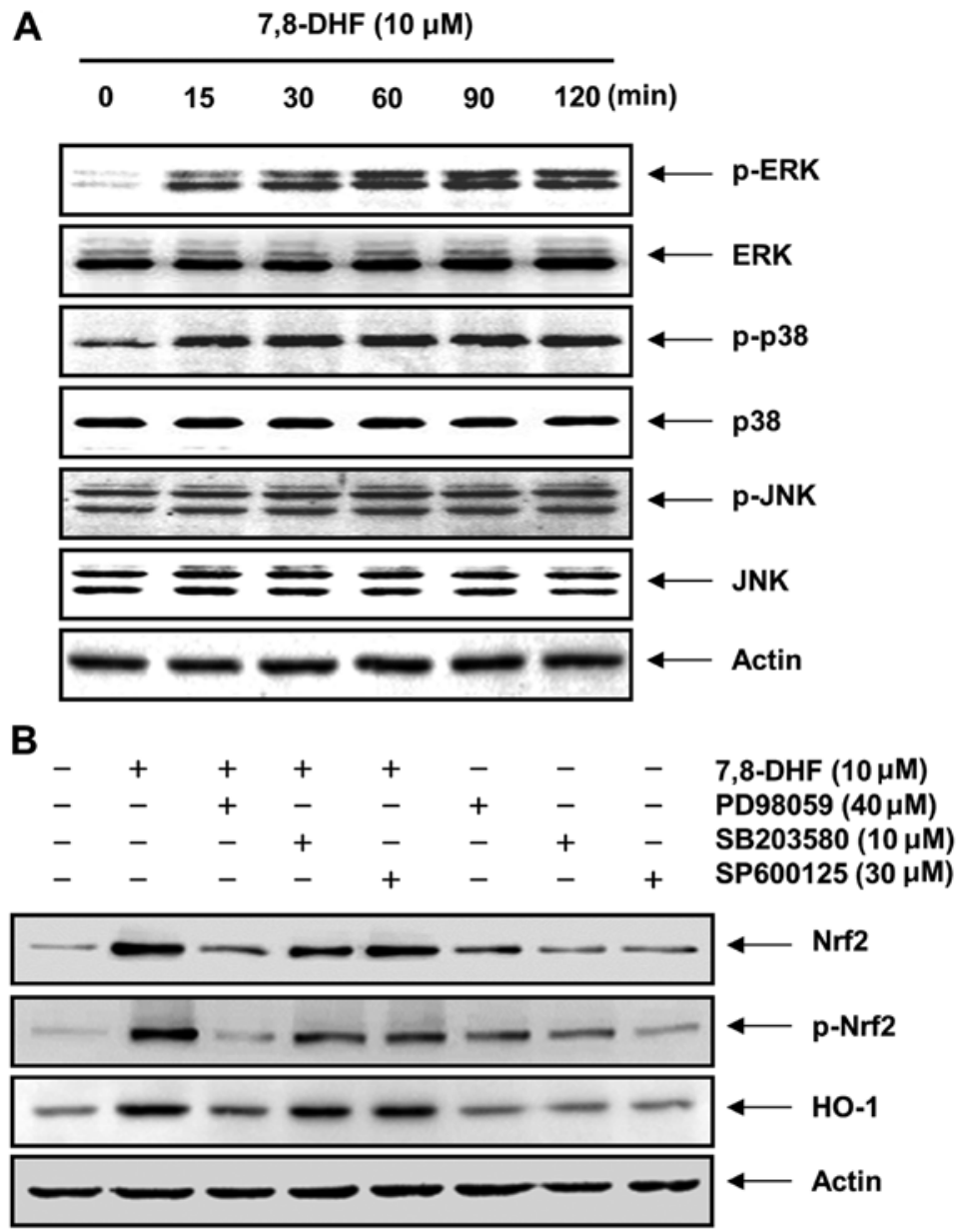

Figure 8. Involvement of the extracellular signal-regulated kinase (ERK) signaling pathway in the nuclear factor-erythroid 2-related factor 2 (Nrf2)-mediated induction of heme oxygenase-1 (HO-1) by 7,8-dihydroxyflavone (7,8-DHF) in C2C12 myoblasts. Cells were treated with $10 \mu \mathrm{M} 7,8$-DHF for the indicated periods of time (A) or pre-treated for $1 \mathrm{~h}$ with or without the indicated inhibitors and then treated with $10 \mu \mathrm{M} 7,8$-DHF for an additional $6 \mathrm{~h}$ (B). The cells were lysed and equal amounts of cell lysates were then separated on SDS-polyacrylamide gels and transferred onto nitrocellulose membranes. The membranes were probed with the indicated antibodies, and the proteins were visualized using an enhanced chemiluminescence (ECL) detection system. Actin was used as an internal control.

tosis and reducing ROS production generated by exposure to $\mathrm{H}_{2} \mathrm{O}_{2}$ (Figs. 1-3). It is well-known that ROS generation is associated with mitochondrial dysfunction, and thus we presumed that 7,8-DHF would improve mitochondrial function by eliminating the overproduction of ROS induced by $\mathrm{H}_{2} \mathrm{O}_{2}$, and thereby reducing $\mathrm{H}_{2} \mathrm{O}_{2}$-induced apoptosis. To assess the oxidative damage induced by $\mathrm{H}_{2} \mathrm{O}_{2}$, we measured both the tail length of DNA using comet assay and the levels of $\mathrm{p}-\gamma \mathrm{H} 2 \mathrm{AX}$ by western blot analyses, which are widely used markers for the detection of DNA damage (25). Our data indicated that exposure to $\mathrm{H}_{2} \mathrm{O}_{2}$ increased the tail length (DNA migration) and the expression of $\mathrm{p}-\gamma \mathrm{H} 2 \mathrm{AX}$; however, these effects were mitigated in the $\mathrm{C} 2 \mathrm{C} 12$ myoblasts by treatment with 7,8-DHF prior to $\mathrm{H}_{2} \mathrm{O}_{2}$ exposure (Fig. 2A and B). Therefore, the attenuation of apoptosis and DNA damage by 7,8-DHF may be associated with its potent antioxidant effects.

Accumulating evidence has demonstrated that HO-1 plays a central role in cellular antioxidant defense in cells $(5,7,9)$. The transcriptional regulation of $\mathrm{HO}-1$ is linked to the transcription factor, Nrf2, which is a key component in protection against oxidative stress. Under normal conditions, Nrf2 is anchored in the cytoplasm by binding to Keap1, which facilitates the ubiquitination and subsequent proteolysis of Nrf2. However, upon exposure to various types of stress, the Nrf2/Keap1 complex is disrupted, leading to the phosphorylation of Nrf2; this is a critical process in the nuclear translocation of Nrf2, as well as its transcriptional activity (5-7). In the present study, 7,8-DHF induced HO-1 expression, as well as the induction of Nrf2 expression and phosphorylation, and the accumulation of Nrf2 in the nucleus (Fig. 4); these results are consistent with those of previous studies showing treatment with other Nrf2 activators, such as berberine (33), $\alpha$-lipoic acid (34), 4-ketopinoresinol (35), genipin (36) and phenethyl isothiocyanate (37). However, in our study, the knockdown of Nrf2 by Nrf2-targeted siRNA markedly abrogated the 7,8-DHF-induced increase in HO-1 expression (Fig. 5A), suggesting that $\mathrm{Nrf} 2$ is a critical upstream regulator of the 7,8-DHF-mediated induction of HO-1 in C2C12 myoblasts. The silencing of Nrf2 abolished the 7,8-DHF-induced restoration of the $\mathrm{H}_{2} \mathrm{O}_{2}$-mediated growth inhibition of $\mathrm{C} 2 \mathrm{C} 12$ myoblasts (Fig. 5B). Pre-treatment with ZnPP, a HO-1 inhibitor, also markedly abrogated the protective effects of 7,8-DHF against the $\mathrm{H}_{2} \mathrm{O}_{2}$-induced ROS generation and growth inhibition (Fig. 6). These results suggest that the Nrf2-dependent induction of HO-1 by 7,8-DHF may, at least in part, participate in the protection against oxidative stress, which is in agreement with the results of other studies $(15,38)$. 
A number of studies have suggested that diverse protein kinases are involved in the signals that trigger Nrf2-Keap1 dissociation and the phosphorylation of $\mathrm{Nrf2}$, as well as the antioxidant-induced activation of the $\mathrm{Nrf} 2 / \mathrm{HO}-1$ signaling pathway. For example, the phenolic glucoside gastrodin stimulated HO-1 expression through the activation of the p38 MAPK/Nrf2 signaling pathway (39), the flavonoid sulfuretin upregulation of the activity of HO-1 through the JNK/ERK/Nrf2 signaling pathway (40), the eckol induction of Nrf2-dependent HO-1 expression through the JNK and $\mathrm{PI} 3 \mathrm{~K} / \mathrm{Akt}$ signaling pathways (41), and the induction of expression of HO-1 by prenylated flavone cudraflavone B mediated through the PI3K/Akt pathway (42). These findings prove that the role of each pathway in the activation of $\mathrm{Nrf} 2 / \mathrm{HO}-1$ signaling, and their molecular targets, may be specific to the stimulus and cell type. In the present study, the PI3K/Akt signaling pathway was rapidly activated following treatment with 7,8-DHF (Fig. 7A). ERK and p38 MAPK, but not JNK, were also markedly activated. To identify which signaling cascade controlsl the activation of Nrf2 by 7,8-DHF, we examined the effects of specific inhibitors of PI3K and MAPKs on the induction of HO-1 and Nrf2, and the phosphorylation of Nrf2. The results demonstrated that $\mathrm{p} 38$ MAPK was not involved in the 7,8-DHF-induced activation of $\mathrm{Nrf} 2 / \mathrm{HO}-1$ signaling, as its inhibitor (SB203580) had no effect on the 7,8-DHF-induced HO-1 and Nrf2 expression and Nrf2 phosphorylation (Fig. 7B). However, both the PI3K inhibitor, LY294002, and the ERK inhibitor, PD98059, suppressed the 7,8-DHF-induced changes in the levels of $\mathrm{HO}$ and Nrf2 (Figs. 7B and 8B), a finding which is consistent with the results of the study by Ryu et al (19). Akt can be activated in a PI3K-dependent manner by various growth and survival factors, and it plays a key role in cell survival and metabolism by binding and regulating a number of downstream effectors. Moreover, previous studies have suggested that Akt kinase phosphorylates specific serine or threonine residues present in Nrf2, thus facilitating the nuclear localization of Nrf2 and thereby inducing HO-1 (6). Recently, it was shown that PI3K inhibitor partially blocked the protective effects of 7,8-DHF, indicating that the PI3K/Akt pathway plays a crucial role in 7,8-DHF-mediated protection (16). On the other hand, among the MAPKs, the activation of the p38 MAPK and JNK pathways has been shwon to lead to the induction of apoptosis through the phosphorylation of a variety of pro-apoptotic downstream effectors, whereas the ERK pathway is more often associated with cell survival (43). Certain studies have also reported that 7,8-DHF prevents oxidative stress-induced cytotoxicity by enhancing ERK signaling $(13,15,19,20)$. Therefore, these observations suggest that PI3K/Akt and ERK play a crucial role in the Nrf2-dependent induction of HO-1 and suggest that Nrf2 is a downstream effector of Akt and ERK, which are activated in response to 7,8-DHF treatment and oxidative stress. Therefore, 7,8-DHF treatment prevents cell injury induced by oxidative damage.

In conclusion, the present study demonstrates that 7,8-DHF induces Nrf2-mediated HO-1 expression, which, at least in part, contributes to a cellular defense mechanism against oxidative stress-induced genotoxic events. We suggest that the cytoprotective effects induced by 7,8-DHF may come directly from scavenging ROS and the activation of the PI3K/Akt and ERK signaling pathways. These findings suggest that 7,8-DHF may have potential for use as a therapeutic agent, as it acts as an antioxidant.

\section{Acknowledgements}

This study was supported by the R\&D program of MOTIE/KEIT (10040391, Development of Functional Food Materials and Device for Prevention of Aging-associated Muscle Function Decrease) and the Blue-Bio Industry Regional Innovation Center (RIC08-06-07) at Dongeui University, as an RIC program under the Ministry of Trade, Industry and Energy of Busan city.

\section{References}

1. Kregel $\mathrm{KC}$ and Zhang $\mathrm{HJ}$ : An integrated view of oxidative stress in aging: basic mechanisms, functional effects, and pathological considerations. Am J Physiol Regul Integr Comp Physiol 292: R18-R36, 2007.

2. Finkel T: Signal transduction by reactive oxygen species. J Cell Biol 194: 7-15, 2011.

3. Venugopal R and Jaiswal AK: Nrf1 and Nrf2 positively and c-Fos and Fra1 negatively regulate the human antioxidant response element-mediated expression of $\mathrm{NAD}(\mathrm{P}) \mathrm{H}$ :quinone oxidoreductase1 gene. Proc Natl Acad Sci USA 93: 14960-14965, 1996.

4. Zhang Y and Gordon GB: A strategy for cancer prevention: Stimulation of the Nrf2-ARE signaling pathway. Mol Cancer Ther 3: 885-893, 2004.

5. Kaspar JW, Niture SK and Jaiswal AK: Nrf2:INrf2 (Keap1) signaling in oxidative stress. Free Radic Biol Med 47: 1304-1309, 2009.

6. Niture SK, Khatri R and Jaiswal AK: Regulation of Nrf2-an update. Free Radic Biol Med 66: 36-44, 2014.

7. Surh YJ, Kundu JK and Na HK: Nrf2 as a master redox switch in turning on the cellular signaling involved in the induction of cytoprotective genes by some chemopreventive phytochemicals. Planta Med 74: 1526-1539, 2008

8. Kweon MH, In Park Y, Sung HC and Mukhtar H: The novel antioxidant 3-O-caffeoyl-1-methylquinic acid induces Nrf2-dependent phase II detoxifying genes and alters intracellular glutathione redox. Free Radic Biol Med 40: 1349-1361, 2006.

9. Jaiswal AK: Nrf2 signaling in coordinated activation of antioxidant gene expression. Free Radic Biol Med 36: 1199-1207, 2004.

10. Wang Y, Chun OK and Song WO: Plasma and dietary antioxidant status as cardiovascular disease risk factors: a review of human studies. Nutrients 5: 2969-3004, 2013.

11. Liu X, Chan CB, Jang SW, Pradoldej S, Huang J, He K, Phun LH, France S, Xiao G, Jia Y, et al: A synthetic 7,8-dihydroxyflavone derivative promotes neurogenesis and exhibits potent antidepressant effect. J Med Chem 53: 8274-8286, 2010.

12. DeviLand OhnoM:7,8-Dihydroxyflavone, a small-molecule TrkB agonist, reverses memory deficits and BACE1 elevation in a mouse model of Alzheimer's disease. Neuropsychopharmacology 37: 434-444, 2012

13. Gupta VK, You Y, Li JC, Klistorner A and Graham SL: Protective effects of 7,8-dihydroxyflavone on retinal ganglion and RGC-5 cells against excitotoxic and oxidative stress. J Mol Neurosci 49: 96-104, 2013.

14. Chen J, Chua KW, Chua CC, Yu H, Pei A, Chua BH, Hamdy RC, $\mathrm{Xu} \mathrm{X}$ and Liu CF: Antioxidant activity of 7,8-dihydroxyflavone provides neuroprotection against glutamate-induced toxicity. Neurosci Lett 499: 181-185, 2011.

15. Zhang R, Kang KA, Piao MJ, Ko DO, Wang ZH, Chang WY, You HJ, Lee IK, Kim BJ, Kang SS and Hyun JW: Preventive effect of 7,8-dihydroxyflavone against oxidative stress induced genotoxicity. Biol Pharm Bull 32: 166-171, 2009.

16. Han XH, Cheng MN, Chen L, Fang H, Wang LJ, Li XT and Qu ZQ: 7,8-Dihydroxyflavone protects PC12 cells against 6-hydroxydopamine-induced cell death through modulating PI3K/Akt and JNK pathways. Neurosci Lett 581: 85-88, 2014.

17. Park HY, Park C, Hwang HJ, Kim BW, Kim GY, Kim CM, Kim ND and Choi YH: 7,8-Dihydroxyflavone attenuates the release of pro-inflammatory mediators and cytokines in lipopolysaccharide-stimulated BV2 microglial cells through the suppression of the NF- $\mathrm{BB}$ and MAPK signaling pathways. Int J Mol Med 33: 1027-1034, 2014. 
18. Park HY, Kim GY, Hyun JW, Hwang HJ, Kim ND, Kim BW and Choi YH: 7,8-Dihydroxyflavone exhibits anti-inflammatory properties by downregulating the NF- $\mathrm{KB}$ and MAPK signaling pathways in lipopolysaccharide-treated RAW264.7 cells. Int J Mol Med 29: 1146-1152, 2012.

19. Ryu MJ, Kang KA, Piao MJ, Kim KC, Zheng J, Yao CW, Cha JW, Chung HS, Kim SC, Jung E, et al: 7,8-Dihydroxyflavone protects human keratinocytes against oxidative stress-induced cell damage via the ERK and PI3K/Akt-mediated Nrf2/HO-1 signaling pathways. Int J Mol Med 33: 964-970, 2014.

20. Ryu MJ, Kang KA, Piao MJ, Kim KC, Zheng J, Yao CW, Cha JW, Hyun CL, Chung HS, Park JC, et al: Effect of 7, 8-dihydroxyflavone on the upregulation of Nrf2-mediated heme oxygenase-1 expression in hamster lung fibroblasts. In Vitro Cell Dev Biol Anim 50: 549-554, 2014.

21. Kim KC, Lee IK, Kang KA, Cha JW, Cho SJ, Na SY, Chae S, Kim HS, Kim S and Hyun JW: 7,8-Dihydroxyflavone suppresses oxidative stress-induced base modification in DNA via induction of the repair enzyme 8-oxoguanine DNA glycosylase-1. Biomed Res Int 2013: 863720, 2013.

22. Kim YS, Li XF, Kang KH, Ryu B and Kim SK: Stigmasterol isolated from marine microalgae Navicula incerta induces apoptosis in human hepatoma HepG2 cells. BMB Rep 47: 433-438, 2014

23. Song JL, Choi JH, Seo JH, Kil JH and Park KY: Antioxidative effects of fermented sesame sauce against hydrogen peroxide-induced oxidative damage in LLC-PK1 porcine renal tubule cells. Nutr Res Pract 8: 138-145, 2014.

24. Jiang R, Teng Y, Huang Y, Gu J, Ma L, Li M and Zhou Y: Preeclampsia serum-induced collagen I expression and intracellular calcium levels in arterial smooth muscle cells are mediated by the PLC- $\gamma 1$ pathway. Exp Mol Med 46: e115, 2014.

25. Rogakou EP, Pilch DR, Orr AH, Ivanova VS and Bonner WM: DNA double-stranded breaks induce histone H2AX phosphorylation on serine 139. J Biol Chem 273: 5858-5868, 1998.

26. Pischke SE, Zhou Z, Song R, Ning W, Alam J, Ryter SW and Choi AM: Phosphatidylinositol 3-kinase/Akt pathway mediates heme oxygenase-1 regulation by lipopolysaccharide. Cell Mol Biol (Noisy-le-grand) 51: 461-470, 2005.

27. Paine A, Eiz-Vesper B, Blasczyk R and Immenschuh S: Signaling to heme oxygenase-1 and its anti-inflammatory therapeutic potential. Biochem Pharmacol 80: 1895-1903, 2010.

28. Yang JJ, Tao H, Huang C and Li J: Nuclear erythroid 2-related factor 2: a novel potential therapeutic target for liver fibrosis. Food Chem Toxicol 59: 421-427, 2013.

29. Woldu AS and Mai J: A novel relationship between the radical-scavenging activity of flavonoids and enthalpy of formation revealed with Hartree-Fock computations and thermochemical deduction. Redox Rep 17: 115-130, 2012.

30. Melidou M, Riganakos K and Galaris D: Protection against nuclear DNA damage offered by flavonoids in cells exposed to hydrogen peroxide: the role of iron chelation. Free Radic Biol Med 39: 1591-1600, 2005.
31. Chapple SJ, Siow RC and Mann GE: Crosstalk between Nrf2 and the proteasome: therapeutic potential of Nrf2 inducers in vascular disease and aging. Int J Biochem Cell Biol 44: 1315-1320, 2012.

32. Chen $K$ and Keaney J: Reactive oxygen species-mediated signal transduction in the endothelium. Endothelium 11: 109-121, 2004.

33. Mo C, Wang L, Zhang J, Numazawa S, Tang H, Tang X, Han X, Li J, Yang M, Wang Z, et al: The crosstalk between Nrf2 and AMPK signal pathways is important for the anti-inflammatory effect of berberine in LPS-stimulated macrophages and endotoxin-shocked mice. Antioxid Redox Signal 20: 574-588, 2014.

34. Deng C, Sun Z, Tong G, Yi W, Ma L, Zhao B, Cheng L, Zhang J, $\mathrm{Cao} F$ and $\mathrm{Yi} \mathrm{D}: \alpha$-Lipoic acid reduces infarct size and preserves cardiac function in rat myocardial ischemia/reperfusion injury through activation of PI3K/Akt/Nrf2 pathway. PLoS One 8: e58371, 2013.

35. Chen HH, Chen YT, Huang YW, Tsai HJ and Kuo CC: 4-Ketopinoresinol, a novel naturally occurring ARE activator, induces the Nrf2/HO-1 axis and protects against oxidative stress-induced cell injury via activation of PI3K/AKT signaling. Free Radic Biol Med 52: 1054-1066, 2012.

36. Jeon WK, Hong HY and Kim BC: Genipin upregulates heme oxygenase-1 via PI3-kinase-JNK1/2-Nrf2 signaling pathway to enhance the anti-inflammatory capacity in RAW264.7 macrophages. Arch Biochem Biophys 512: 119-125, 2011.

37. Xu C, Yuan X, Pan Z, Shen G, Kim JH, Yu S, Khor TO, Li W, Ma J and Kong AN: Mechanism of action of isothiocyanates: The induction of ARE-regulated genes is associated with activation of ERK and JNK and the phosphorylation and nuclear translocation of Nrf2. Mol Cancer Ther 5: 1918-1926, 2006.

38. Koriyama Y, Nakayama Y, Matsugo S and Kato S: Protective effect of lipoic acid against oxidative stress is mediated by Keap1/ Nrf2-dependent heme oxygenase-1 induction in the RGC-5 cell line. Brain Res 1499: 145-157, 2013.

39. Jiang G, Hu Y, Liu L, Cai J, Peng C and Li Q: Gastrodin protects against MPP(+)-induced oxidative stress by up regulates heme oxygenase-1 expression through p38 MAPK/Nrf2 pathway in human dopaminergic cells. Neurochem Int 75: 79-88, 2014

40. Lee DS, Kim KS, Ko W, Li B, Jeong GS, Jang JH, Oh H and Kim YC: The cytoprotective effect of sulfuretin against tert-butyl hydroperoxide-induced hepatotoxicity through Nrf2/ARE and JNK/ERK MAPK-mediated heme oxygenase-1 expression. Int J Mol Sci 15: 8863-8877, 2014.

41. Jun YJ, Lee M, Shin T, Yoon N, Kim JH and Kim HR: eckol enhances heme oxygenase-1 expression through activation of Nrf2/JNK pathway in HepG2 cells. Molecules 19: 15638-15652, 2014.

42. Lee J and Kim S: Upregulation of heme oxygenase-1 expression by dehydrodiconiferyl alcohol (DHCA) through the AMPK-Nrf2 dependent pathway. Toxicol Appl Pharmacol 281: 87-100, 2014.

43. Boutros T, Chevet E and Metrakos P: Mitogen-activated protein (MAP) kinase/MAP kinase phosphatase regulation: Rroles in cell growth, death, and cancer. Pharmacol Rev 60: 261-310, 2008. 